Technical Note

\title{
Innovative Solution for Reducing the Run-Down Time of the Chipper Disc Using a Brake Clamp Device
}

\author{
Andrea Colantoni ${ }^{1, *}$ (D) , Francesco Mazzocchi ${ }^{1}$, Vincenzo Laurendi ${ }^{2}$, Stefano Grigolato ${ }^{3}$, \\ Francesca Monarca ${ }^{1}$, Danilo Monarca ${ }^{1}$ and Massimo Cecchini ${ }^{1}$ \\ 1 Department of Agricultural and Forestry Sciences (DAFNE), Tuscia University, 01100 Viterbo, Italy; \\ mazzocchi@unitus.it (F.M.); francescamonarca@hotmail.it (F.M.); monarca@unitus.it (D.M.); \\ cecchini@unitus.it (M.C.) \\ 2 INAIL National Institute for Insurance against Accidents at Work, Via di Fontana Candida 1, \\ 00078 Monte Porzio Catone (RM), Italy; v.laurendi@inail.it \\ 3 Department of Land, Environment, Agriculture and Forestry, Università degli Studi di Padova, Viale \\ dell'Università 16, 35020 Legnaro, Italy; stefano.grigolato@unipd.it \\ * Correspondence: colantoni@unitus.it; Tel.: +039-076-135-7356
}

Received: 18 July 2017; Accepted: 17 August 2017; Published: 20 August 2017

\begin{abstract}
Wood-chippers are widely used machines in the forestry, urban and agricultural sectors. The use of these machines implies various risks for workers, primarily the risk of contact with moving and cutting parts. These machine parts have a high moment of inertia that can lead to entrainment with the cutting components. This risk is particularly high in the case of manually fed chippers. Following cases of injury with wood-chippers and the improvement of the technical standard (ComitéEuropéen de Normalisation-European Norm) EN 13525: 2005 + A2: 2009, this technical note presents the prototype of an innovative system to reduce risks related to the involved moving parts, based on the "brake caliper" system and electromagnetic clutch for the declutching of the power take-off (PTO). The prototype has demonstrated its potential for reducing the run-down time of the chipper disc $(95 \%)$ and for reducing the worker's risk of entanglement and entrainment in the machine's feed mouth.
\end{abstract}

Keywords: wood chipper; brake clamp; work safety; forestry

\section{Introduction}

The research activities reported in this article were conducted in the framework of the "Protection of machinery operators against crush, entanglement, shearing" (PROMOSIC) project funded by the Italian National Institute for Accidents at Work Insurance (INAIL). The project covered a number of safety issues associated with most widely used agricultural machines and the article describes a prototype solution for forestry chippers with manual feeds.

Data on the occurrence of accidents provide an objective index of the danger of machinery as well as a valid reason for identifying the most critical features of these machines. At present, there is no database covering Italy and all Europe for reporting significant accident data associated with chippers, so analyses of accident indexes compiled in other countries were helpful. In North America, 2042 non-lethal accidents involving chippers and 31 deaths in the decades of 1992-2002 were reported.

An in-depth analysis of the fatal accidents disclosed that $42 \%$ involved work in gardening, $16 \%$ were related to ground-keeping work, and the remainder involved workers in the forestry and agricultural sectors [1]. These analyses also turned up the point that $68 \%$ of the accidents were caused by workers' direct contact with the mechanical components of the machinery in operation, and contact 
with mechanical components not during chipping operations accounted for $29 \%$ of the accidents due to the open protective case of the drum or disk chipper still in motion. The largest number of fatal accidents was concentrated each year in the period between July and August. Again, in North America, it was found that the social cost of fatal accidents with chippers came to US $\$ 28.5$ million in 2003. Analyses of the non-lethal accidents showed that the majority of cases involved workers aged $25-34$ and that $60 \%$ of the accidents caused immediate injury or amputation of parts of the upper-body limbs. For $25 \%$ of these injuries, the victims were unable return to work for periods of up to 30 work days [2]. Further studies indicated that $16 \%$ of these accident victims had less than three months of experience in that particular job and $18 \%$ of them had worked from three to 11 months on their jobs [3-5]. Safety in the use of machinery is, and has been in the past, a strongly pertinent problem at the European and specifically at the Italian level. The specifics of chippers, however, are actually only applied at the European Union level, with the technical (European Standard EN) regulation on safety specifically targeted to manufacturers. The technical standard was set out in the Machinery Directive EN 13525:2005 + A2:2009 on forestry machinery, mobile chippers and safety. Following a formal French objection due to accidents in 2011 and 2012, this standard with C1-type harmonization has been superseded [1]. The choice of work to perform with a chipper depends mainly on request and continuity of use (type of work and quantity of chips), characteristics of materials to feed in (the origin), and the work system (productivity and work on site). The chipping machines used in forestry, agriculture and on urban greenery are usually mobile types coupled with a tractor and are mounted, trailed or semi-mounted and for energy production by agro-forestal biomass [6,7]. They can be mounted on a truck with an independent engine, or driven by the tractor or self-propelled. Chippers in the low power category $(<20 \mathrm{~kW})$ can be equipped for transport and an internal combustion engine or electric motor. The project PROMOSIC has been involved with the Italian manufacturer Peruzzo Ltd. (Curtarolo, Italy) which made a number of portable chipper models available for preliminary trials for evaluating the risk for operators during manual feeding and the time needed for stopping the chipper components, disks or knives in specific cases [8]. The leading safety feature in the use of chippers is, in fact, the danger of coming into contact with the internal flywheel. This component continues to rotate by inertia even if the safety bar is inserted. According to EN 13525: $2005+$ A2:2009, the safety bar installed in the bottom of the machine and on the sides of the feed chute is mandatory. The safety bar acts to block the feed rotors, stopping them completely in a quarter of a second, but the flywheel continues to rotate by inertia for more than a minute $[4,5,9-14]$. The consequences are the potential for dragging the worker into the chipping chamber to the chipping components, which is the major cause of serious or fatal accidents.

\subsection{Manually Fed Wood-Chippers}

Manually fed wood-chippers (or self-feeding mobile wood-chippers) are commonly used in small businesses or in the domestic maintenance of rural land and small forest stands as well as urban woodlands, urban parks and gardens for small tree-trimming operations and/or for comminution of small branches [15].

Generally, a manually fed wood-chipper consists of a feeding hopper, a rotating chipper unit, a power unit and a discharge system. Branches and small logs or trees are fed manually into the feeding hopper and thus pulled into the chipping unit. In detail, self-feeding mobile wood-chippers are commonly used during tree-trimming operations and consist of a self-loaded frame, a feed chute, knives mounted on a rotating disc or drum or as an alternative to an auger, a discharge unit and a power unit (using power take-off or an independent diesel power unit or electric engine).

The biomass is first entered manually by the operator into the machine's in-feed chute and then the grabbing mechanism feeds it towards the chipper unit. The chipper disc or drum rotating generally between 1000 and $2000 \mathrm{rpm}$ is able to comminute the biomass in regular small wood pieces (woodchips) [16]. Through the expulsion mechanism the woodchips are discharged on the ground or into a bin or carrier (Figure 1). 
A distinction between several models in the market, whether manual or load-type machines, is found in the type of drum chipper, disc and auger chipper. In drum chippers, the cutting device consists of a steel rotor rotating around its longitudinal axis and two to 24 tangential knives or hammers can be inserted (lower quality of the obtained product). The maximum cutting diameter is one-third of the diameter of the drum (diameter from 500 to $1500 \mathrm{~mm}$ ). In the wood-chippers, the cutting member (minimum of $800 \mathrm{~mm}$ ) is made up of a flywheel which usually consists of two to four radially oriented knives [17-19]. In this case, the maximum cutting diameter corresponds to one-quarter of the disc chipper diameter.

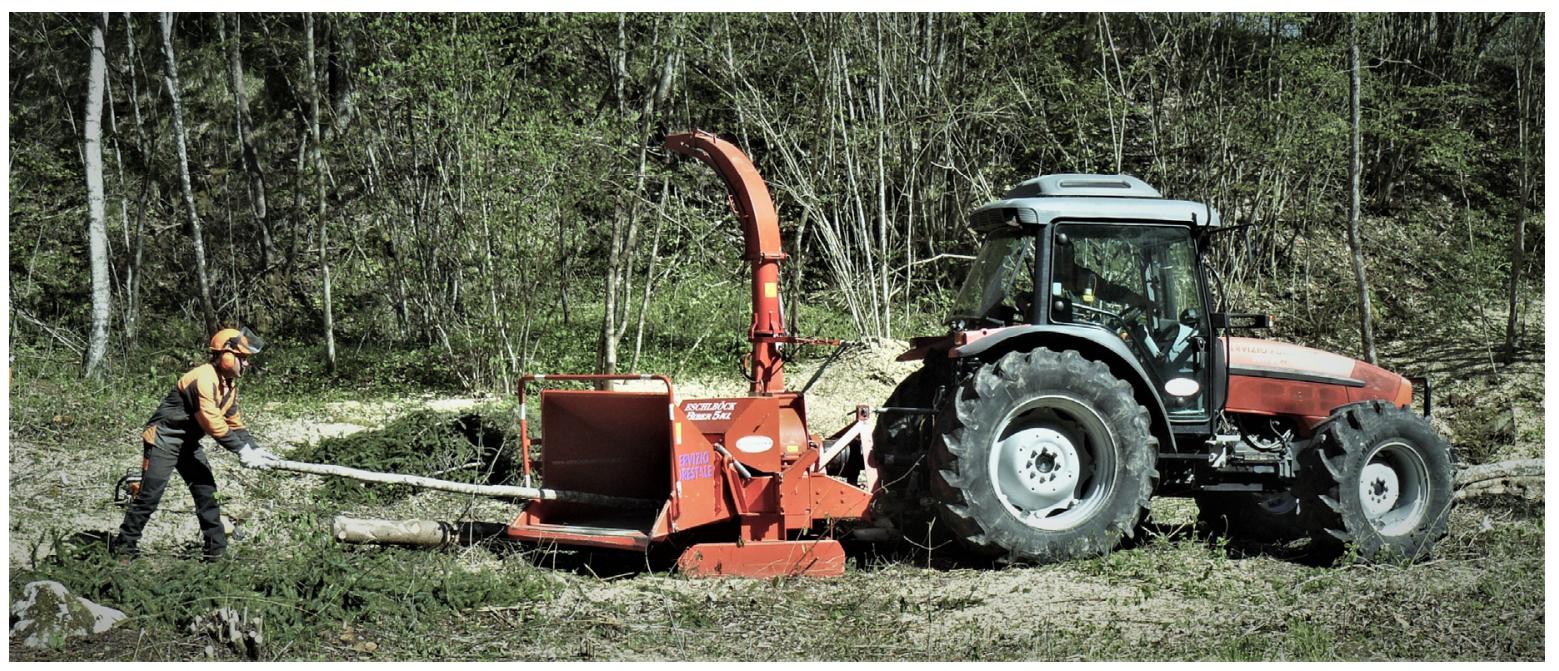

Figure 1. Manually fed wood-chipper used in a riverbank vegetation clearing cut.

\subsection{Specific Hazards of the Manually Fed Wood-Chipper}

Chipper machines can lead to different risks, in particular direct contact with the sharpened components of the machine such as knives inserted into the drum or disk. Contact with the chipper's operating components (blades, discs or knives) may result in amputation or death. Workers may also be injured by material thrown from the machine. To minimize these hazards, appropriate engineering and work practice controls, including worker training, should be guaranteed.

Working with or around a wood-chipper can be dangerous and might result in death or serious injury if proper procedures are not followed. Workers feeding material into the self-feeding wood-chippers are at risk of being pulled into the chipper if they are entangled in the branches being fed into the machine. In addition, workers are at risk of being struck by unlatched, improperly secured, damaged or improperly maintained hoods that may be thrown from the wood-chipper after contact with the rotating chipper knives.

\subsection{Development of an Innovative Solution}

Peruzzo Ltd. made a "TIREX" chipper model (Figure 2) available for trials which mounted the three-point hitch of a tractor in order to test a disengagement chipper brake system as an innovative safety solution. In this specific case, the chipping components were made up of four knives fitted on a rotating disk and a fixed counter-blade mounted on the bodywork of the machine. The feeding system consisted of a horizontal toothed roller and chain, both powered by hydraulics to convey materials to the fixed cutting disc knives. The feeding chute rollers can be stopped or their direction of rotation reversed simply with the use of a control lever. A standard no-stress system with an hour counter automatically regulated correct branches feeding with power supplied in relation to the power required by the materials to ease the work of the chipping components and the engine. The disengagement chipper brake system was made up of an electromagnetic clutch mounted on the chipper drive 
shaft; a steel caliper brake; a hydraulic electro-valve for brake control; and an emergency button with normally closed $(\mathrm{NC}$; closed $=$ short circuit = creating a path for the current) and normally open $(\mathrm{NO}$; open = open circuit $=$ not creating a path for the current $)$ contact. When a normally open push-button is pressed, a path is provided for the current. When a normally closed push-button is pressed, the current is impeded from flowing.

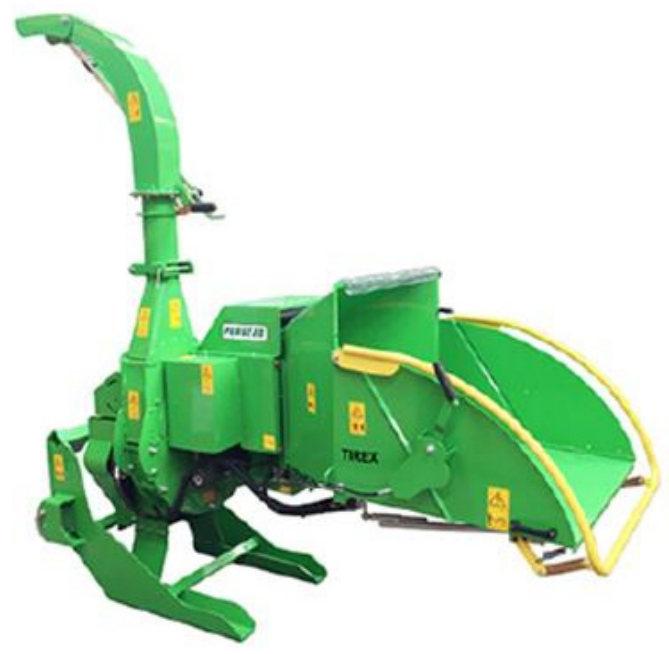

Figure 2. The manually fed wood-chipper used for developing the brake clamp device system (picture by Peruzzo).

NC push-buttons are used in emergency stop buttons. They are pressed when an accident has occurred or may occur, and the machine needs to be stopped immediately due to an action which could damage someone or something. Normally closed buttons are preferred for two reasons: firstly, they do not rely on creating good contact to create a signal. They just have to open a circuit, which is much easier. An NC is more robust and therefore safer. Secondly, they react quicker. For an NO button, the signal event happens at the end of the movement (when the movable part makes contact). For an NC button, the signal event happens at the beginning of the movement (when the movable part stops making contact), through a $12 \mathrm{~V}$ hydraulic flow regulator actuating as a brake plug with a no-stress CPU (central processing unit). In light of the components considered for completing the system, the cost is estimated to be around $€ 900$. This cost was calculated on the building of a prototype. The cost could be substantially lowered if the system became integrated in the serial production of these machines. In conclusion, the solutions studied could be useful for reducing accidents due to entanglement and dragging with relatively small costs. Moreover, the no-stress system moderating power turns out to be needed for work with the combination of the electromagnetic clutch.

\section{Materials and Methods}

\subsection{The Wood-Chipper Used}

For developing an innovative system for lowering the cut-off time of the cutting disc, it was decided to base the study on one of the most globally used machine configurations most commonly used in green maintenance in the internal business environment.

All the tests were performed in 2017 at the "Lucio Toniolo" experimental farm of the University of Padova in cooperation with Peruzzo Ltd. The chipper chosen is a type of driven chipper powered by power take-off tractors of between 30 and $60 \mathrm{~kW}$. The machine has a cutting member consisting of a flywheel with a thickness of $30 \mathrm{~mm}$ and diameter of $620 \mathrm{~mm}$, on which two knives are inserted with a width of $200 \mathrm{~mm}$ and a thickness of $25 \mathrm{~mm}$. The feeding system is made up of a plan, whereby 
two rollers are provided to convey the material to the chipping chamber. Vertical oscillation rollers are hydraulically actuated and controlled by a block control.

\subsection{The Run-Down Time Evaluation}

For the machine found in current market conditions, the stopping times of the flywheel have been verified, following disconnection of the power outlet, by a decoupling device of the power outlet from the universal joint (Figure 3).

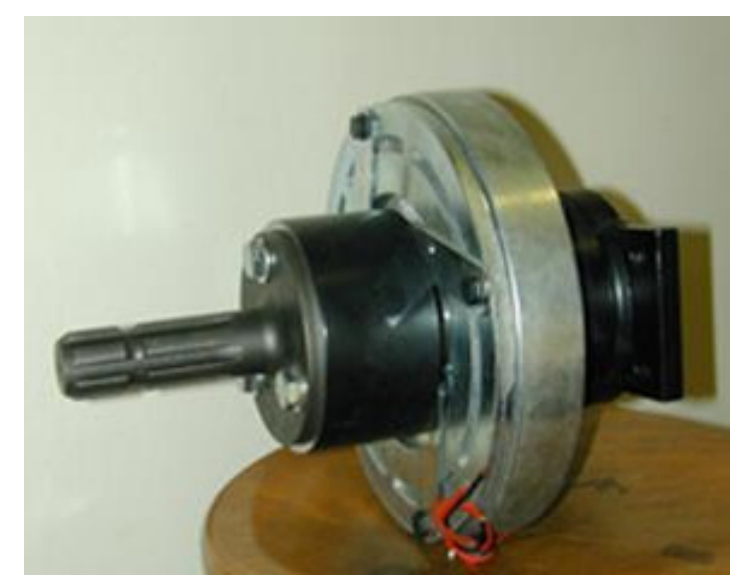

Figure 3. Decoupling system installed between power outlet and cardan shaft.

The tests predicted the activation of the decoupling system, both in absence and in the presence of chipping material. Tests firstly provided for a maximum rotation of the flywheel, corresponding to $1400 \mathrm{rpm}$, then activating the decoupling system and disconnecting the power outlet from the shaft. The stopping time has been calculated as from the disengagement moment until the flywheel is fully stopped. The analysis was set by observing the spin speed of the flywheel on the display of the machine's anti-stress system and by slow motion via a dedicated camera.

\subsection{Braking System Design}

The use of a motorcycle brake caliper mounted in the power intake shaft (additional component), specifically a Honda CBR 600 with a vacuum mass of $180 \mathrm{~kg}$ has been suggested.

Below, calculations are used to determine the braking torque necessary to curb the inside of the chipper in a $4 \mathrm{~s}$ time (ex-post condition) with respect to the current state. The calculation method can be applied indifferently to flywheels, even of different dimensions (Table 1).

Table 1. Data for calculation of braking torque for brake clamp device.

\begin{tabular}{cc}
\hline \multicolumn{2}{c}{ Initial Data } \\
\hline Diameter & $0.6 \mathrm{~m}$ \\
Radius & $0.3 \mathrm{~m}$ \\
Mass & $80 \mathrm{~kg}$ \\
Angular Speed & $157 \mathrm{rad} / \mathrm{s}$ \\
Stop Time & $4 \mathrm{~s}$ \\
\hline
\end{tabular}

Angular acceleration $\mathrm{a}_{\text {ang }}$ was calculated as:

$$
\mathrm{a}_{\mathrm{ang}}=\frac{\omega_{\text {final }}-\omega_{\text {initial }}}{t}=\frac{0-157}{4}=39.25 \mathrm{rad} \mathrm{s}^{-2}
$$

where $\omega_{\text {final }}$ is the final angular speed and $\omega_{\text {initial }}$ is the initial angular speed (rad/s). 
Then, the moment of inertia I, can be calculated (I):

$$
\mathrm{I}=\frac{m \times r^{2}}{2}+\frac{80 \times 0.09}{2}=3.6 \mathrm{~kg} \mathrm{~m}^{2}
$$

where $m$ is the mass $(\mathrm{kg})$ and $r$ is the radius $(\mathrm{m})$.

Finally, the braking torque $\mathrm{C}_{\text {braking }}$ is calculated:

$$
\mathrm{C}_{\text {braking }}=\mathrm{I} \times \mathrm{A}_{\text {ang }}=3.6 \times 39.25=141.3 \mathrm{Nm}
$$

Based on the braking torque, a hydraulic "clamp" was dimensioned, suitable for the dimensional characteristics of the internal flywheel.

\section{Results and Discussion}

\subsection{Flywheel Stop Times, with and without Chipping Material and Disconnection of Power Take-Off}

In the test, the insertion of the decoupling system had to be combined with the anti-stress system. The anti-stress system, consisting of a control unit and a sensor for measuring the speed of the flywheel rotation, controls the feed of the chipping chamber, avoiding overload situations, through the speed control of the feed rollers (Figure 4).
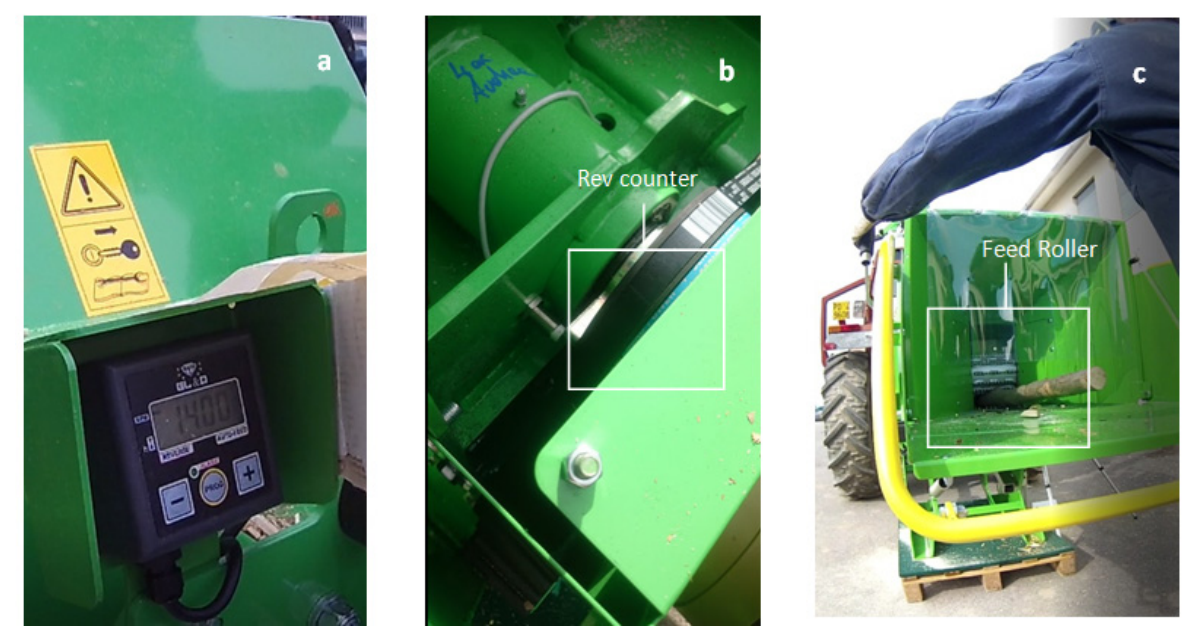

Figure 4. Anti-stress system installed in the tested machine.

In case the chipping flywheel is impacted by a material overload and decreases the number of revolutions, the anti-stress system effectively blocks the entry of further material into the chipping chamber by locking the feed rollers.

The anti-stress system is activated when the flywheel rotation speed drops below a certain number of revolutions per minute (rpm). Since inserting the power take-off decoupling system leads to the breaking of the drive torque at the chipping wheel, there is an immediate effect on the rotational speed, which begins to decrease immediately. As a result, the anti-stress system is activated immediately (if present and if inserted), which effectively blocks the feed of the chipping chamber.

If the anti-stress system is off or not present, the power system will continue to work for a few seconds after the power outlet is disconnected, without actually blocking the power supply of the material to the chipping chamber. It could therefore result in the real risk of damage to the machine and the same flywheel and chipping chamber, rather than blocking any contact between the operator and flywheel (Table 2). Also, in the best of cases, after removing the cause of the block, the machine, in a subsequent work phase, can strike a new flywheel block even with little time from the start of the new chipping phase, failing to work the plant material (an example of the material that locked the 
flywheel in Figure 5). This may require the operator to intervene by removing the crankcase and the protections on the chipper (to remove the vegetal material from the flywheel knives), creating high-risk situations for workers. This can also occur for small diameters.

Table 2. Flywheel stop times in relation to different conditions.

\begin{tabular}{cc}
\hline Condition & Average Stop Times (s) \\
\hline Absence of material & 79 \\
During drumming (with no stress system inserted) & 73 \\
During stacking (with no stress system inserted) & 76 \\
\hline
\end{tabular}

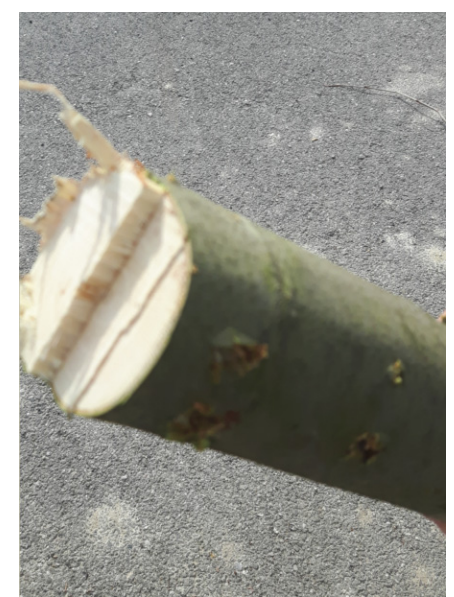

Figure 5. Detail of the blocking branch.

\subsection{Design for Chipper Disengagement and Brake Design and Prototype Design and Implementation}

The aim of the study is to provide a solution that allows synergic decoupling with the disc braking of a chipper, coupled with a forest tractor. Current safety devices do not allow the machine to be disengaged and brake-coupled to a tractor, as it does not guarantee the safety of operators.

The chipper consists of a rotating disk where four knives are mounted and a counter blade fixed in the frame of the machine, which can chip wood up to a diameter of $18 \mathrm{~cm}$. The chip size may vary according to the needs by adjusting the knives and feed rollers of the product. The feed rollers are hydraulically driven, with a no-stress device to preserve disk blades. If necessary, the power cycle can be reversed or stopped. The discharge of the product takes place through a swivel and $360^{\circ}$ rotating tube.

\section{Technical Aspects of the Brake Clamp Device}

The brake clamp device is composed of the following components (Figure 6):

(a) An electromagnetic clutch mounted on the tractor's cardan shaft; the wood-chipper's disc cutter is made up of a steel ring $600 \mathrm{~mm}$ in diameter and $30 \mathrm{~mm}$ thick, which mounts four knives with a total mass of $\sim 90 \mathrm{~kg}$. Supplied with a tractor of $70-80 \mathrm{~kW}$, considering that the disc can rotate about $1500 \mathrm{rpm}$, we have a torque of $33 \mathrm{Nm}$. The electromagnetic clutch chosen has a diameter of $173 \mathrm{~mm}$, and it works at a voltage of $12 \mathrm{~V}$ with a maximum power absorption of $68 \mathrm{~W}$. It resists at a maximum torque of $47 \mathrm{Nm}$.

(b) The brake clamp of a motorcycle type mounted on Power Take Off (Figure 7). A "motorcycle" brake clamp was chosen, in particular a Honda CBR 600 with a $180 \mathrm{~kg}$ vacuum mass. Considering the driver and passenger $(140 \mathrm{~kg})$, the total estimated mass is about $320 \mathrm{~kg}$. Divided for two motor pliers we have a load of $160 \mathrm{~kg}$ per gripper. The braking disc diameter of the bike is $300 \mathrm{~mm}$, and at a speed of $130 \mathrm{~km} / \mathrm{h}$, the disc rotates at $2300 \mathrm{rpm}$ with a peripheral speed of $36 \mathrm{~m} / \mathrm{s}$. 
The disk of the chipper machine in question rotates at a speed of $1500 \mathrm{rpm}$, considering:

- $\quad$ mounting a $\varnothing 300 \mathrm{~mm}$ brake disc will give a peripheral speed of $23.5 \mathrm{~m} / \mathrm{s}$

- the brake mass $=160 \mathrm{~kg}$

- the peripheral speed drive disk $\varnothing 300 \mathrm{~mm}=36 \mathrm{~m} / \mathrm{s}$ (brake disc mass $=80 \mathrm{~kg}$ )

- the peripheral speed of brake disc Ø300 $\mathrm{mm}=23.5 \mathrm{~m} / \mathrm{s}$

- $\quad$ the chipper disc stop time (estimated) $=4 \mathrm{~s}$

(c) The brake disc $\varnothing 300 \mathrm{~mm}$ in stainless steel is mounted in the inlet PTO shaft.

(d) There are three lectro valves to control the brake clamp device.

(e) An emergency stop.

(f) A hydraulic flow regulator to set the brake actuation.

(g) A $12 \mathrm{~V}$ power plug.

(h) Anti-stress safety systems.

The brake clamp device patented phase has the application number 102017000052858.

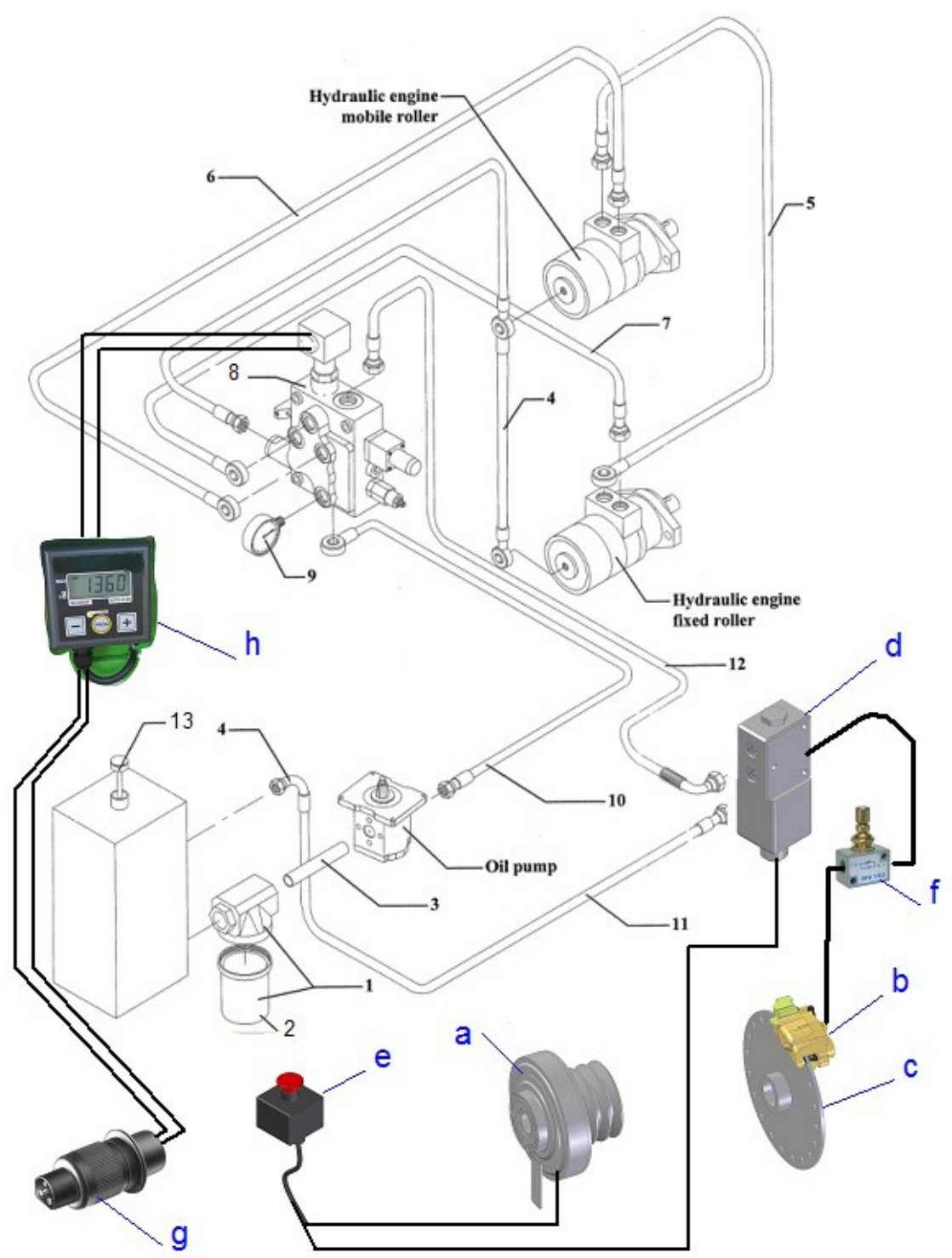

Figure 6. Components to be added to the standard machine (description in the text). 


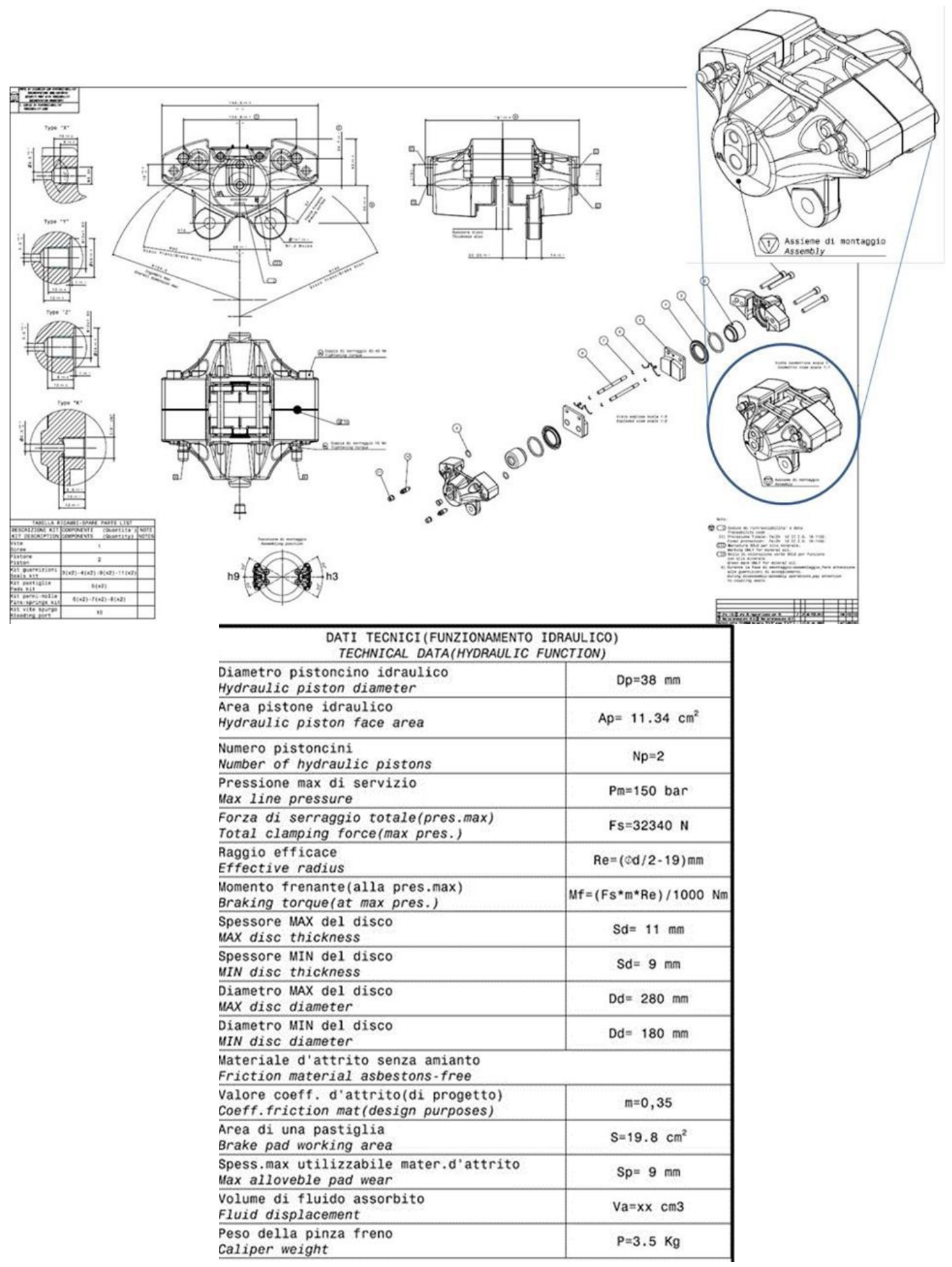

Figure 7. Brake clamp technical data.

\section{Conclusions}

The main objective of reducing and/or eliminating the risk of operator entrapment in the mechanical part of the chipper has been met through the design of appropriate prevention and protection systems to be applied directly to the chipper. The reduction of component stop times and the consequent risk reductions were achieved with relatively simple and cost-effective technology 
which can be applied to most cutting machines on the market. In addition, the decoupling system, in combination with anti-stress safety systems of the machine, was effective. A further step forward will be the realization of a prototype that acts on the inertia of the flywheel, blocking it in a timely approach thanks to a braking system whose effectiveness will be quantified in further tests. From the point of view of the technical regulations, the requests from the French Authorities for the amendment of EN 13525 have been taken into account. The experience gained suggests that these changes can certainly improve the safety of the chippers.

Acknowledgments: This study was supported by the "Protection of agricultural machinery operators from crush, entanglement, shearing" (PROMOSIC) project, funded by INAIL. The authors wish to thank Marco Vieri of the University of Florence for his help in the decoupling system test, and Peruzzo Ltd.

Author Contributions: The authors contributed in the equality in the paper.

Conflicts of Interest: The authors declare no conflict of interest.

\section{References}

1. Hallock, G.G. Mutilating shredder/chipper hand injuries. Ann. Plast. Surg. 1994, 33, 8-12. [CrossRef]

2. Marsh, S.M.; Fosbroke, D.E. Trends of occupational fatalities involving machines, United States, 1992-2010. Am. J. Ind. Med. 2015, 58. [CrossRef] [PubMed]

3. Özden, S.; Nayir, I.; Göl, C.; Ediş, S.; Yilmaz, H. Health problems and conditions of the forestry workers in Turkey. Afr. J. Agric. Res. 2011, 6. [CrossRef]

4. Marucci, A.; Monarca, D.; Cecchini, M.; Colantoni, A.; Cappuccini, A. The heat stress for workers employed in laying hens houses. J. Food Agric. Environ. 2013, 11, $20-24$.

5. Di Giacinto, S.; Colantoni, A.; Cecchini, M.; Monarca, D.; Moscetti, R.; Massantini, R. Dairy production in restricted environment and safety for the workers. Industrie Alimentari 2012, 51, 5-12.

6. Colantoni, A.; Allegrini, E.; Boubaker, K.; Longo, L.; Di Giacinto, S.; Biondi, P. New insights for renewable energy hybrid photovoltaic/wind installations in Tunisia through a mathematical model. Energy Convers. Manag. 2013, 75, 398-401. [CrossRef]

7. Colantoni, A.; Evic, N.; Lord, R.; Retschitzegger, S.; Proto, A.R.; Gallucci, F.; Monarca, D. Characterization of biochars produced from pyrolysis of pelletized agricultural residues. Renew. Sustain. Energy Rev. 2016, 64, 187-194. [CrossRef]

8. Pickett, W.; Hagel, L.; Dosman, J.A. Safety Features on Agricultural Machines and Farm Structures in Saskatchewan. J. Agromed. 2012, 17. [CrossRef] [PubMed]

9. Lindroos, O.; Aspman, E.W.; Lidestav, G.; Neely, G. Accidents in family forestry's firewood production. Accid. Anal. Prev. 2008, 40. [CrossRef] [PubMed]

10. Hoque, M.; Sokhansanj, S.; Naimi, L.; Bi, X.; Lim, J. Review and analysis of performance and productivity of size reduction equipment for fibrous materials. In Proceedings of the 2007 ASABE Annual International Meeting, Minneapolis, MN, USA, 17-20 July 2007; Volume 3, pp. 1-18. [CrossRef]

11. Spinelli, R.; Hartsough, B.R.; Magagnotti, N. Testing Mobile Chippers for Chip Size Distribution. Int. J. For. Eng. 2005, 16, 29-35. [CrossRef]

12. Poje, A.; Spinelli, R.; Magagnotti, N.; Mihelic, M. Exposure to noise in wood chipping operations under the conditions of agro-forestry. Int. J. Ind. Ergon. 2015, 50, 151-157. [CrossRef]

13. Magagnotti, N.; Picchi, G.; Sciarra, G.; Spinelli, R. Exposure of Mobile Chipper Operators to Diesel Exhaust. Ann. Occup. Hyg. 2014, 58, 217-226. [PubMed]

14. De Martino, G.; Massantini, R.; Botondi, R.; Mencarelli, F. Temperature affects impact injury on apricot fruit. Postharvest Biol. Technol. 2002, 25, 145-149. [CrossRef]

15. Rottensteiner, C.; Tsioras, P.; Neumayer, H.; Stampfer, K. Vibration and noise assessment of tractor trailer and truck-mounted chippers. Silva Fennica 2013, 47, 1-14. [CrossRef]

16. Spinelli, R.; Magagnotti, N.; Deboli, R.; Preti, C. Noise emissions in wood chipping yards: Options compared. Sci. Total Environ. 2016, 563, 145-151. [CrossRef] [PubMed]

17. Struttmann, T.W. Fatal and Nonfatal Occupational Injuries Involving Wood Chippers-United States, 1992-2002. Morb. Mortal. Wkly. Rep. 2004, 53, 1130-1131. 
18. A.M.D. Forestry Machinery-Wood Chippers-Safety, 2nd ed.; BSI: London, UK, 2005; pp. 1-46, ISBN 9780580 624759.

19. Moscetti, R.; Frangipane, M.T.; Monarca, D.; Cecchini, M.; Massantini, R. Maintaining the quality of unripe, fresh hazelnuts through storage under modified atmospheres. Postharvest Biol. Technol. 2012, 65, 33-38. [CrossRef] 